\title{
An Analysis of the Economic Impact of US Presidential Elections Based on Principal Component and Logical Regression
}

\author{
Jing-Jing Wang $\mathbb{D},,^{1,2}$ Yan Liang $\mathbb{D},^{3}$ Jin-Tao Su $\mathbb{D}^{3},{ }^{3}$ and Jia-Ming Zhu $\mathbb{D}^{4}$ \\ ${ }^{1}$ School of Foreign Languages, Soochow University, Suzhou 215006, China \\ ${ }^{2}$ School of Languages and Media, Anhui University of Finance and Economics, Bengbu 233030, China \\ ${ }^{3}$ Institute of Finance, Anhui University of Finance and Economics, Bengbu 233030, China \\ ${ }^{4}$ Institute of Quantitative Economics, Anhui University of Finance and Economics, Bengbu 233030, China \\ Correspondence should be addressed to Jia-Ming Zhu; zhujm1973@163.com
}

Received 26 January 2021; Revised 4 March 2021; Accepted 10 March 2021; Published 23 March 2021

Academic Editor: Shaohui Wang

Copyright (c) 2021 Jing-Jing Wang et al. This is an open access article distributed under the Creative Commons Attribution License, which permits unrestricted use, distribution, and reproduction in any medium, provided the original work is properly cited.

\begin{abstract}
Economy is one of the major issues in the United States presidential election campaign. In order to investigate the impact of the US presidential election on the economy, this paper first constructs an analysis model of the economic impact on the United States based on stepwise regression and principal component analysis to analyze the focus of different candidates' attention on the economic issues and its possible impact on the US economy in the election year and after the election; secondly, a Chinese economic impact analysis model based on factor analysis and machine learning logistic regression was constructed to analyze the impact of the US presidential election on the Chinese economy. At the same time, the future economic development of the United States and China based on the time series prediction model is forecast and analyzed, respectively. Finally, the countermeasures and policy suggestions on China's related economic development are put forward.
\end{abstract}

\section{Introduction}

As we all know, an election for the President of the United States occurs every four years. The 2020 United States presidential election was scheduled for Tuesday, November 3, 2020. The Republican candidate Donald Trump and Democratic candidate Joe Biden have different policy views on finance, trade, economics, environmental governance, and other key development areas. They have great differences in prevention measures, domestic infrastructure construction, tax policy, environmental protection policy, medical endowment insurance policy, employment policy, foreign trade policy, immigration policy, and national education policy.

Different candidates will shape different strategic development models for the social and economic development of the United States. At the same time, the development strategy model of global economy and finance will change accordingly because of the election of different candidates. Trump had adopted many sanctions against China's economic development during his term of office, and Biden's current policy is mainly to ease tensions with China. The election of different candidates as the President of the United States will not only have a different impact on China's economic development but also have a greater impact on the United States economy. This study has the practical significance regarding the current Chinese economic development and American economic development.

This paper mainly studies the following problems. (i) Using relevant data to quantitatively analyze the possible impact of election of different candidates on the American economy. (ii) Using relevant data to quantitatively analyze the possible impact of the election of different candidates on the Chinese economy. (iii) To put forward suggestions on the policies concerning the economic development of China.

\section{Literature Review}

There are many policy and theoretical studies on Sino-US relations at home and abroad. Trump took office from 2016 to 2020 , so there is a lot of literature on Trump and analysis 
of Trump's policy. But Biden is still in the presidential candidate stage, has limited influence in American politics, and has less literature on him. Among them, domestic and foreign scholars on Trump's policy analysis are as follows.

Jing Chen [1] argues that US President Donald Trump made a series of radical remarks about trade relations with the Asia-Pacific region during the campaign and after taking office and adopted relatively radical policies in both multilateral and bilateral areas. This has aroused the concern of the major trading partners of the United States in the AsiaPacific region, has an important impact on the global strategy and foreign policy of the United States, has brought uncertainty to the development of Sino-US relations and the United States Asia-Pacific alliance system, and will affect the economic and security situation in the Asia-Pacific region.

Ming-Ming $\mathrm{Wu}$ [2] believes that, since the establishment of diplomatic relations between China and the United States, the bilateral trade between China and the United States has developed rapidly. China is the largest trading partner of the United States, and the United States is the second largest trading partner of China. However, with the rapid development of the bilateral trade between China and the United States, there are also some unfavorable factors between the two countries, which lead to Sino-US trade friction.

Ji-Wu Yin [3] believes that the construction, stability, and change of national consensus are the basis for the development of bilateral relations and the change of regional cooperation. The strategic consensus between China and the United States can be analyzed in four dimensions: relationship nature, policy bottom line, behavior norm, and benefit cognition. The factors that influence and shape the stability of Sino-US strategic consensus after Trump came to power include leadership personality, leadership style and team, structural factors of China and the United States, and their cognition. In general, Trump's leadership personality plays a greater role in the early days of Trump's administration, while leadership style and team, structural factors between China and the United States, and their cognition will affect the strategic consensus between China and the United States in the medium and long term, among which strength contrast and domestic political factors are the core factors of the evolution of strategic consensus between China and the United States in the future.

Wang and Sun [4] believed that Trump was elected as the new president in the 2016 US election. His comments on China in the election partly reflect the dissatisfaction of the grassroots in the American society with the Sino-US trade. At present, Trump and his diplomatic team and the Republican mainstream are tough on China at the Sino-US trade level; they are more inclined to unilateralism and arms development on security issues and strengthen the United States' efforts to restrict China in the Asia-Pacific region. Sino-US relations face greater uncertainty on core hot issues such as Taiwan and the South China Sea.

\section{Basic Assumptions}

In order to solve the problem, we make assumptions as follows: (i) Assume that the data consulted are true and reliable

(ii) Assume that the data evaluation of the total value of the policy implementation of the United States Government is included in the indicators

(iii) Assume that the selected indicators have reasonable economic significance

(iv) Assume that the policy claims of the two candidates in the United States can have a significant impact on the results of the model analysis

\section{Analysis of the Possible Impact on the US Economy of the Election of Different Candidates Based on Principal Components}

4.1. Research Thought. First of all, from the value of the policies of the President of the United States, extract two presidential candidates in finance, trade, economic, environmental governance, and other key development areas of key policies to construct five representative indicators. (i) Infrastructure (FA). (ii) Taxes (TP). (iii) Environmental investment (EN). (iv) Employment (EM). (v) Market value (MV). Secondly, through the correlation analysis method and according to the correlation coefficient test results to establish a stepwise regression model, the stepwise regression equation of five indexes and the coefficients of each index are obtained. Then, the principal component analysis method is used to establish the principal component analysis model to solve the weight of the five indexes. The weight level of each indicator represents the degree to which the US presidential candidate attaches importance to this area of economic development and the level of influence that presidential candidates may have on the development of the United States economy.

\subsection{Analysis Procedure}

4.2.1. Correlation Analysis of Different Economic Indicators. Correlation analysis is to judge whether there is a correlation between economic indicators. The correlation thermodynamic diagram can be obtained by correlation analysis of five indexes, as shown in Figure 1.

The correlation diagram can clearly show the correlation of each index, and the deeper the color, the higher the correlation degree. Through the test results of the relevant thermodynamic diagram, we can know that the correlation degree between the indexes is strong, and there is a relationship of mutual influence, and it is a representative, which can be used for the following analysis and judgment.

4.2.2. Analysis of Different Indicators Based on Stepwise Regression Analysis. After the correlation test of the five indexes, SPSS software is used to analyze the selected indexes in stepwise regression. The stepwise regression method can test all the variables contained in the regression equation and select the factors that have the greatest influence on the explanatory variables from the other factors to test their significance until no factors can be introduced $[5,6]$. The results of the stepwise 


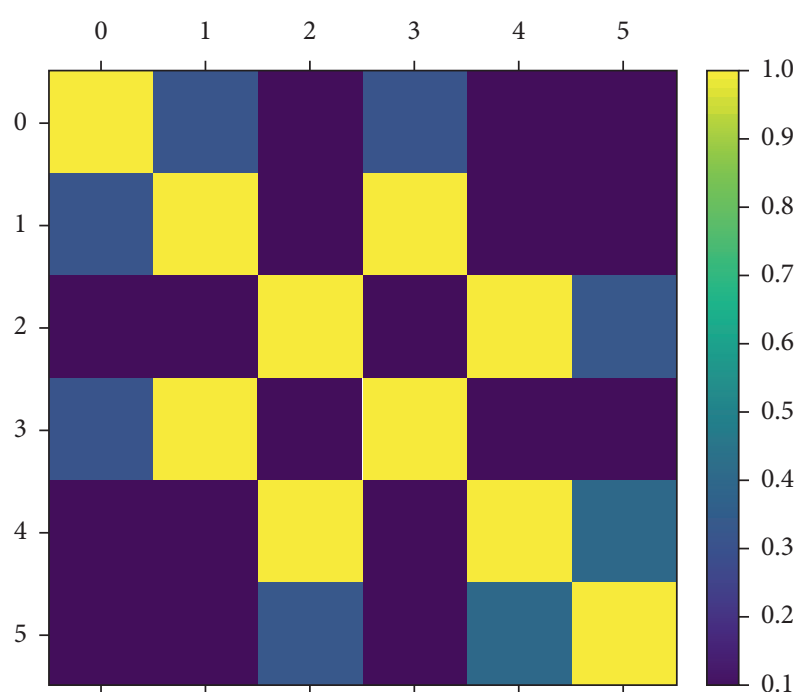

FIgURE 1: Thermal map of the correlation of indicators in the United States.

regression of the five indexes are obtained by software construction of the stepwise regression model, as shown in Table 1.

Joint significance test: the original hypothesis $H_{0}: \beta_{0}=\beta_{1}=\beta_{2}=\beta_{3}=0$, and the alternative hypothesis $H_{1}: \beta_{1}, \beta_{2}, \beta_{3}$ are not all zero. Table 1 shows that the original hypothesis is rejected at $95 \%$ confidence level, and the alternative hypothesis is accepted that the coefficient is not all 0 . The coefficient of determination $R^{2}=0.88$, and the overall significance level of the model is high. The regression equation between the five indexes can be obtained by stepwise regression:

$Y=-0.024 \mathrm{MV}-2.394 \mathrm{TP}+0.075 \mathrm{FA}+0.024 \mathrm{EN}-3.524 \mathrm{EM}$.

By analyzing the stepwise regression equation, we can get the negative correlation between market value, tax quota, and environmental protection investment, while the relationship between infrastructure and employment is positive.

In order to determine whether there is a maximum or minimum value in the model, the accuracy of the data analysis results is affected. The residual error and lever value diagram are used to analyze the data of the five indexes. The residual error and lever value diagram are shown in Figure 2.

Cook distance is used to determine whether a point is an extreme point in residual and leverage analysis. If the Cook distance is greater than 0.5 , the point can be considered as a strong impact point. 1 and 0.5 in Figure 2 are contours with Cook distances of 1 and 0.5 , respectively. Cook distance greater than 0.5 is only two points 7856 and 2078. Most of the data fall below the contours of 1 and 0.5 indicating that most of the data are normal. There is no maximum or minimum. In general, the stepwise regression model basically does not have more maximum or minimum points.

\subsubsection{Establishment and Solution of the Principal Component} Analysis Model. Principal component analysis, also called principal component analysis or matrix data analysis, is a multivariate statistical analysis method that converts some measured variables into less irrelevant comprehensive indexes. In the analysis of practical problems, the first few largest principal components are often selected [7-9].

Suppose $X_{1}, X_{2}, \ldots, X_{5}$ are five treated indexes, and the new variable index and the $F$ value meet the following relationship:

$$
\left\{\begin{array}{l}
F_{1}=a_{11} X_{1}+a_{12} X_{2}+\ldots+a_{5} X_{5}, \\
F_{2}=a_{21} X_{1}+a_{22} X_{2}+\ldots+a_{25} X_{5}, \\
F_{m}=a_{m 1} X_{1}+a_{m 2} X_{2}+\ldots+a_{m 5} X_{5} .
\end{array}\right.
$$

By using the principal component analysis method, the five indexes are analyzed and solved. The concrete analysis steps are as follows: first, the correlation coefficient matrix of the five indexes is calculated by SPSS software, and then, the total variance between the five main components is calculated. The results are shown in Tables 2 and 3 .

From the analysis of Tables 2 and 3, the market value and employment situation have the greatest influence on the total value of the American presidential policy, which is the main factor. Because the impact of environmental investment on the total value fluctuation is very small, it is ignored here. Then, the five variables infrastructure, tax quota, environmental protection investment, employment situation, and market value are analyzed and verified, and finally, the weight of the five indicators is obtained. The weight is summarized in Table 4 .

By calculating the weight of the five economic indicators, we can get the economic impact of the US presidential candidate on various development fields in the United States. The greater the weight, the greater the impact of the field on the US presidential policy and the greater the importance of the field after the future presidential candidate is elected. Among them, market value and employment have the greatest impact on the US presidential policy, giving it the highest weight, while infrastructure, tax quotas, and environmental investment have less impact on the US presidential policy, and the weight given to them is smaller.

4.2.4. Prediction of Time Series. Combined with the analysis results of five indexes, the total value index is obtained by integrating them. In order to predict the future development of the total value index after the presidential candidate is elected, the SPSS software is used to predict the total value index in time series, and the possible development trend of the index in the future economic development is obtained. The prediction diagram is shown in Figure 3.

Figure 3 shows that the impact of policies implemented in the United States on the society fluctuates greatly. During the campaign period, due to the impact of social and economic development, the total value fluctuates greatly around 2020 and will gradually improve and stabilize in the later period.

\section{Analysis on the Impact of Machine Learning Logical Regression on China's Economy}

5.1. Research Thought. Firstly, according to the basic direction of finance, economy, infrastructure, trade, employment, and taxation and combined with the possible 


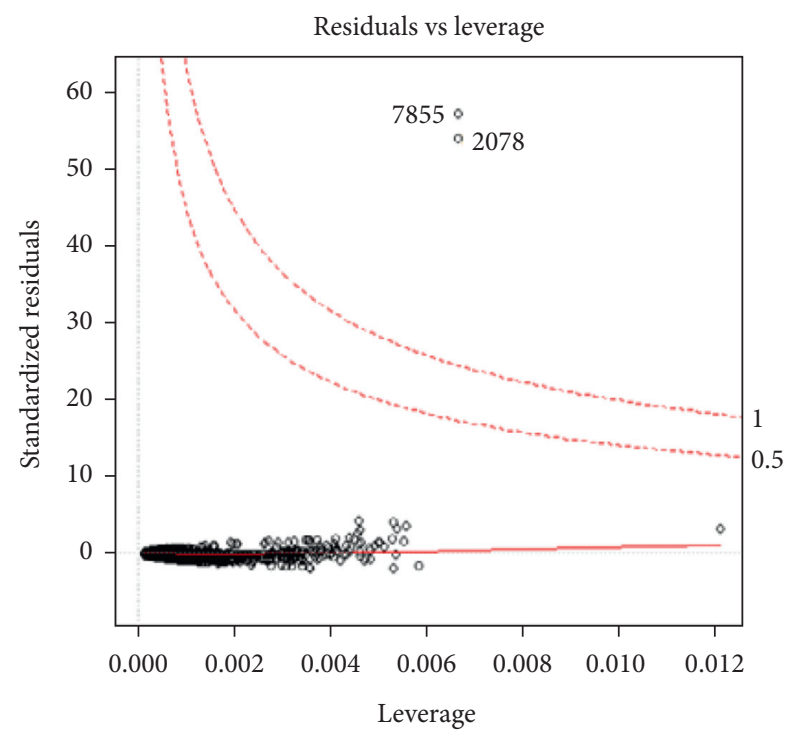

— Cook's distance

FIgURE 2: Residual and lever values.

TABLE 1: The United States indicator of stepwise regression results.

\begin{tabular}{|c|c|c|c|c|c|c|}
\hline Total score & Coef. & St. err. & $t$-value & $p$-value & Confidence (\%) & Interval \\
\hline $\mathrm{MV}$ & -0.024 & 0.020 & -1.17 & 0.241 & -0.063 & 0.017 \\
\hline $\mathrm{TP}$ & -2.394 & 0.078 & -30.11 & $\leq 0.001$ & -2.650 & -2.238 \\
\hline FA & 0.075 & 0.027 & 2.84 & 0.005 & 0.021 & 0.128 \\
\hline $\mathrm{EN}$ & 0.024 & 0.001 & 28.63 & $\leq 0.001$ & 0.032 & 0.025 \\
\hline EM & -3.524 & 0.048 & - & $\leq 0.001$ & -3.594 & -2.856 \\
\hline Mean dependent var. & $\leq 0.001$ & SD-dependent var. & 0.010 & & & \\
\hline$R$-squared & 0.88 & Number of obs. & 10000.000 & & & \\
\hline$F$-test & 319.571 & Prob $>F$ & $\leq 0.001$ & & & \\
\hline Akaike crit. (AIC) & -64652.206 & Bayesian crit. (BIC) & -64624.374 & & & \\
\hline
\end{tabular}

Note. MV, TP, FA, EV, and EM are market value, tax quota, infrastructure, employment situation, and environmental protection investment.

TABLE 2: Correlation coefficient.

\begin{tabular}{lcccrr}
\hline Correlation coefficient & LX 1 & LX 2 & LX 3 & LX 4 & LX 5 \\
\hline LX 1 & 1.000 & 0.973 & 0.234 & 0.601 & -0.053 \\
LX 2 & 0.973 & 1.000 & 0.367 & 0.492 & -0.213 \\
LX 3 & 0.234 & 0.367 & 1.000 & 0.185 & -0.225 \\
LX 4 & 0.601 & 0.492 & 0.185 & 1.000 & 0.656 \\
LX 5 & -0.053 & -0.213 & -0.225 & 0.656 & 1.000 \\
\hline
\end{tabular}

TABLE 3: Explanation of total variance.

\begin{tabular}{lccccc}
\hline Constituent & \multicolumn{3}{c}{ Initial eigenvalue } & \multicolumn{2}{c}{$\begin{array}{c}\text { Extract the square sum of the load } \\
\text { Variance percentage }\end{array}$} \\
& Total & Variance percentage & Cumulate (\%) & Total & Cute (\%) \\
\hline 1 & 3.436 & 57.251 & 57.251 & 3.436 & 57.251 \\
2 & 1.653 & 27.574 & 84.824 & 1.653 & 27.574 \\
3 & 0.804 & 13.410 & 98.234 & - & - \\
4 & 0.065 & 1.062 & 99.295 & - & - \\
5 & 0.037 & 0.632 & 99.928 & - & - \\
\hline
\end{tabular}

TABLE 4: Summary of weights.

\begin{tabular}{lccccc}
\hline Indicators & Market value & Infrastructure & Employment & Taxes & Environmental investment \\
\hline Weight & 0.402 & 0.132 & 0.206 & 0.135 & 0.127 \\
\hline
\end{tabular}




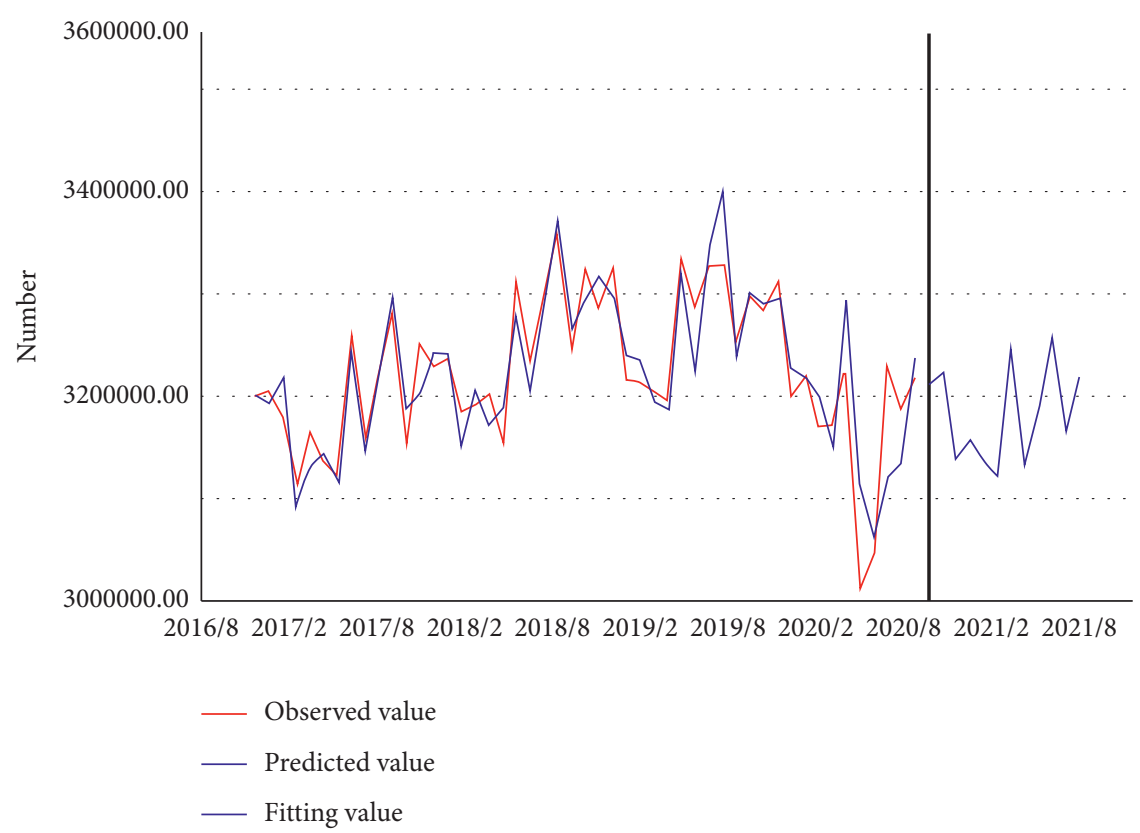

Figure 3: Total value of the time series forecast trend in the United States.

impact of the US election on China's economy, some appropriate basic indicators are selected to collect relevant data and process the data. Secondly, the factor analysis method is used to reduce the dimension of the basic indicators collected, and the six indexes of finance, economy, infrastructure, trade, employment, and tax can be obtained by analysis, and the total value is calculated. Then, the coefficient weight of each index is solved by the machine learning logic regression method, and the influence degree of the American election on China's economy is analyzed. Finally, the time series prediction of the six indexes and the total value is carried out to obtain the possible trend of the future economy, so as to facilitate the timely adoption of corresponding policy measures to promote the long-term stable development of the economy.

\subsection{Analysis Procedure}

5.2.1. Data Collection and Processing. According to the basic directions of finance, economy, and infrastructure and the possible impact of the US election on China's economy, 22 basic indicators are selected, including the current value of import and export, the cumulative growth of fixed assets investment, the current revenue of the state finance, and the end value of the money supply. After selecting the index, collect the relevant data, fill in the missing value, and make the standardization processing. The data standardization formula is as follows:

$$
X_{i}^{*}=\frac{X_{i}-E\left(X_{i}\right)}{\sqrt{D\left(X_{i}\right)}} .
$$

Note: $E\left(X_{i}\right)$ is the sample mean and $D\left(X_{\mathrm{i}}\right)$ is the sample variance.
5.2.2. Study on Different Indicators Based on Factor Analysis. Factor analysis is a multivariable statistical analysis method, which is based on the interdependence of the required variables and ascribes some overlapping and complex variables to a few comprehensive factors. The basic ideas are as follows. Establish $X=\left(X_{1}, X_{2}, \cdots, X_{P}\right) \prime$ is a dimensional random vector whose linear changes are as follows. Factor analysis is a multivariable statistical analysis method, which is based on the interdependence of the required variables and ascribes some overlapping and complex variables to a few comprehensive factors $[10,11]$. The basic ideas are as follows. Let it be a dimensional random vector whose linear variation is as follows:

$$
\begin{aligned}
& P C_{1}=a_{1}^{\prime} X=a_{11} X_{1}+a_{21} X_{2}+\cdots+a_{p 1} x_{p}, \\
& P C_{2}=a_{2}^{\prime} X=a_{12} X_{1}+a_{22} X_{2}+\cdots+a_{p 2} x_{p}, \\
& P C_{p}=a_{p}^{\prime} X=a_{1 p} X_{1}+a_{2 p} X_{2}+\cdots+a_{p p} x_{p} .
\end{aligned}
$$

In practical applications, $m(m<p)$ principal components are usually selected ( $m$ represents the number of principal components). The number of principal components should be determined according to the cumulative variance contribution rate of each principal component. Cumulative contribution is

$$
\lambda=\frac{\sum_{k=1}^{m} \lambda_{k}}{\sum_{i=1}^{p} \lambda_{i}}
$$

$\lambda$ is the eigenvalue corresponding to each principal component; $k$ is the selected principal component; and $i$ is the total principal component.

The KMO test is carried out by using the SPSS first, and it is found that the matrix is a nonpositive definite matrix, but because the factor analysis only selects the common factor with the cumulative variance contribution rate greater than $85 \%$, the nonpositive definite matrix has no significant effect 
on the factor analysis results. By calculating the common factor variance of each data index, it can be concluded that the extraction value of all the data indexes is greater than 0.5 , which indicates that the 22 different factor indexes selected by the model are successfully expressed. There is a certain applicability in the principal component analysis model. The results are shown in Table 5.

The variance contribution rate of each factor can be obtained by analyzing the main factor eigenvalue and cumulative contribution rate. The cumulative contribution rate of the first six factors is $86.632 \%$. It can be considered that the first four factors can replace $86.632 \%$ of the information of all variables. According to the component score coefficient, dimensionality reduction yields six representative indicators. (i) Finance (FC). (ii) Economic (EC). (iii) Infrastructure (IF). (iv) Trade (TE). (v) Employment (OE). (vi) Taxation (TR). and, calculate the total value. Here is a normal test of the value that outputs the histogram and trend line of the normality test, as shown in Figures 4 and 5 . Through analysis, it can be concluded that the total index data are in accordance with normal distribution.

5.2.3. Correlation Analysis of Different Indicators. For the 6 indexes, Pearson correlation coefficient and statistical test, correlation thermodynamic diagram, and correlation coefficient table are obtained, as shown in Figure 6 and Table 6. The correlation thermodynamic diagram can clearly show the correlation of each column feature, and the deeper the color, the higher the correlation degree. The correlation between different indexes can be obtained directly through the correlation coefficient table.

Through the correlation thermodynamic diagram and correlation coefficient table, it can be concluded that the correlation degree of the total value with economy and infrastructure is relatively high, and the correlation between other indexes is certain, so regression analysis can be carried out.

5.2.4. Establishment and Solution of the Logical Regression Model for Machine Learning. Before making the regression model, the trend chart of variables is analyzed, and the linear trend chart is obtained by analyzing the linear relationship between dependent variables and independent variables by the scatter plot. The results are shown in Figure 7.

From the analysis of Figure 7, we can get the linear relationship between the six indexes and the total value.

Use Anaconda to call jupyter, and introduce logistic regression; logical regression is a generalized linear regression, which has many similarities with multiple linear regression analysis, the model form is basically the same, and Logical regression belongs to supervised machine learning [12-14]. Upload the six index data to the Anaconda directory with the total value as the target forecast value and the remaining data as the attribute value. When regression, the sample data is first segmented, $75 \%$ of the sample data is used as the training set and $25 \%$ as the test set. The MAE, MSE, RMSE, and $\mathrm{r} 2$ are used as evaluation indicators. The regression function can be obtained as follows:

$$
\begin{aligned}
y= & 0.0016+0.299 \mathrm{FC}+0.2652 \mathrm{EC}+0.123 \mathrm{IF} \\
& +0.0697 \mathrm{TE}+0.0603 \mathrm{OE}+0.0491 \mathrm{TR} .
\end{aligned}
$$

The influence of different indexes on the total value can be obtained from the equation, in which the influence of finance, economy, and infrastructure is greater. Therefore, it can be seen that the overall impact of the promotion of different leaders on China is mainly reflected in the financial, economic, and other aspects. In order to test the fitting effect of the model, $25 \%$ of the collected data is taken as the test set, and the comparison diagram between the predicted value and the real value is made, as shown in Figure 8.

5.2.5. Time Series Prediction. For the purpose of reasonably predicting the future development of the six indicators and the total value after the election of the US presidential candidate, the SPSS software is used to predict the trend of the six indicators and the integrated total value, respectively. The analysis results are shown in Figures 9 and 10 [15-19]. By analyzing the forecast results, we can see that China's indicators and total value will fluctuate in the future, but the overall trend is good.

\section{Countermeasures and Policy Suggestions on China's Economic Development in the US General Election}

For policy recommendations, this paper mainly uses the text mining model and emotional analysis model. First, it collects text data related to the American folk presidential election and uses Python software to carry out text mining and emotional analysis. The results are analyzed, and the countermeasures and policy suggestions in the field of economic development in China are obtained.

6.1. Establishment and Solution of the Emotional Analysis Model. In the traditional statistical model environment based on sparse features, the dictionary composed of words and the emotional polarity score of words are very effective in the task of emotional analysis. The combination of the emotion dictionary and word vector can improve the accuracy of emotion analysis to a certain extent [20,21]. Text data collection and collation of US government policies and comments based on American folk are used as sample data for emotional analysis, and then, polarity analysis is carried out using the third-party natural language-processing library of Python software, and the polarity result diagram of emotional analysis is obtained, as shown in Figure 11.

0 represents the frequency of the distribution of American people's support for Trump's emotional will as the new US president, while 1 represents the frequency of the distribution of American people's support for Biden's emotional will as the new US president. According to Figure 11, most people in the United States support Biden as the new president of the United States, while the number of people who support Trump as the new president of the United States is lower than the number of people who 
TABle 5: Principal factor eigenvalues and cumulative contribution rates.

\begin{tabular}{|c|c|c|c|c|c|c|}
\hline \multirow{2}{*}{ Constituent } & \multicolumn{3}{|c|}{ Initial eigenvalue } & \multicolumn{3}{|c|}{ Extract the square sum of the load } \\
\hline & Total & Variance percentage & Cumulate (\%) & Total & Variance percentage & Cumulate (\%) \\
\hline 1 & 6.578 & 29.900 & 29.900 & 6.578 & 29.900 & 29.900 \\
\hline 2 & 5.834 & 26.517 & 56.417 & 5.834 & 26.517 & 56.417 \\
\hline 3 & 2.706 & 12.300 & 68.717 & 2.706 & 12.300 & 68.717 \\
\hline 4 & 1.534 & 6.971 & 75.688 & 1.534 & 6.971 & 75.688 \\
\hline 5 & 1.327 & 6.034 & 81.722 & 1.327 & 6.034 & 81.722 \\
\hline 6 & 1.080 & 4.911 & 86.632 & 1.080 & 4.911 & 86.632 \\
\hline
\end{tabular}

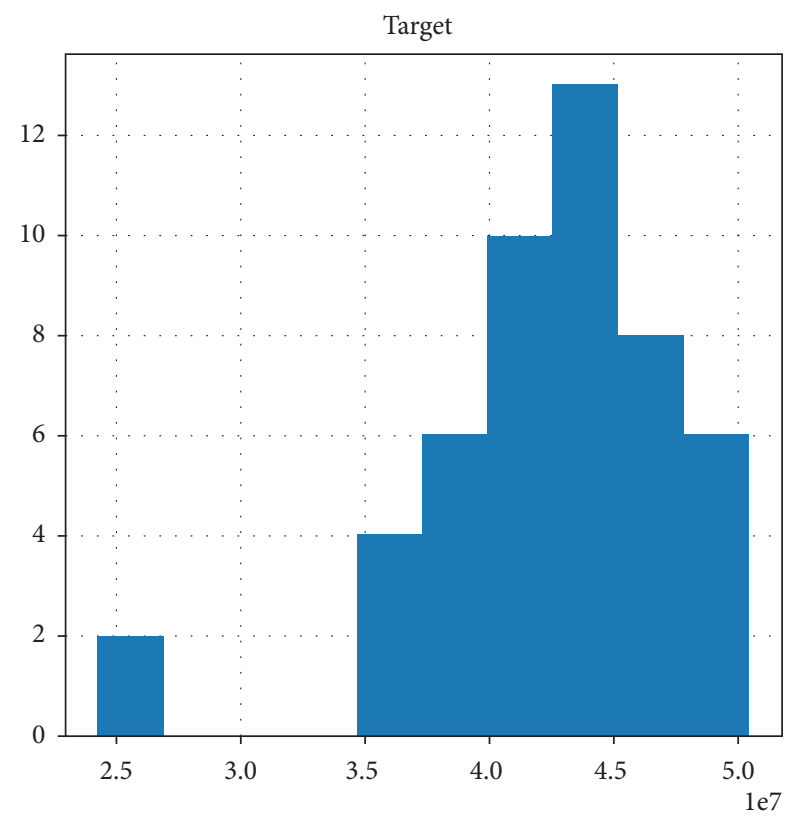

FIgURE 4: Histogram of the normal test.

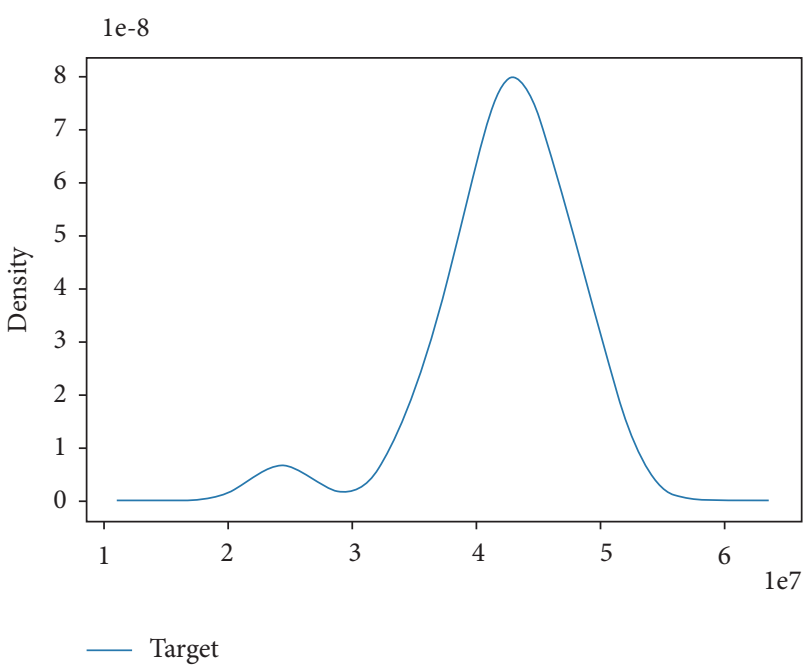

FIgURE 5: Trend diagram of the normal test.

support Biden, indicating Trump's weak advantage in the 2020 election. For the centrist Americans, they are less certain about the two US presidential candidates, and their emotional attitude is not as strong as those who support Biden or Trump.

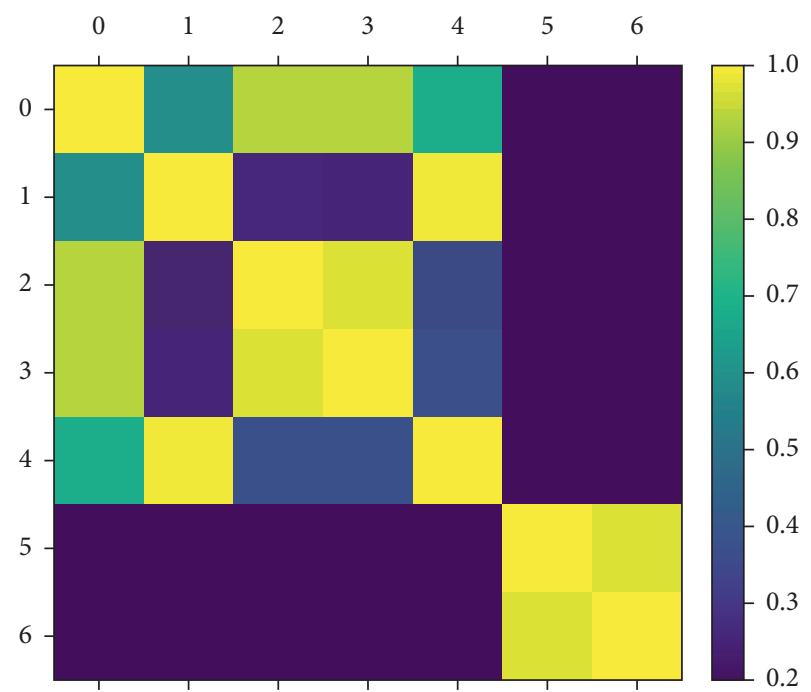

Figure 6: Correlation thermodynamic diagram.

6.2. Establishment and Solution of the Text Mining Model. Text mining model is a process of extracting text information from an unstructured text by establishing a model and obtaining information of interest to users or information that users feel useful [22-24]. Import text files into computer software for text mining to draw word cloud maps, as shown in Figure 12.

According to the analysis of Figure 12, Trump and Biden account for the vast majority of the cloud in the policy documents issued by the US government, followed by "tax," "income," "policy," "market," "stock," "industry," "energy," "infrastructure," "medical," and other keywords appear on the cloud map. According to the previous analysis, Trump has received extensive attention from American folk in tax quota and tax rate, infrastructure construction, market value and scale, and medical endowment insurance policy. At the same time, Biden and Trump still have a large political opposition in the field of economic development.

6.3. Countermeasures and Policy Recommendations for China's Economic Development. For Chinese economic development, from the impact of the US election on the Chinese economy and the analysis of the American policy, from finance, environmental protection, infrastructure, and foreign trade, six different fields of employment and taxation provide corresponding countermeasures and policy suggestions. 
TABLE 6: Correlation coefficient table.

\begin{tabular}{lccccccc}
\hline Correlation & Target & FC & EC & IF & TE & OE \\
\hline Target & 1.000000 & 0.595718 & 0.927189 & 0.927384 & 0.681964 & -0.489510 & -0.693808 \\
FC & 0.595718 & 1.000000 & 0.274233 & 0.267020 & 0.988239 & -0.991312 & -0.987734 \\
EC & 0.927189 & 0.274233 & 1.000000 & 0.966209 & 0.367195 & -0.146737 & -0.383567 \\
IF & 0.927384 & 0.267020 & 0.966209 & 1.000000 & 0.386570 & -0.148863 & -0.399159 \\
TE & 0.681964 & 0.988239 & 0.367195 & 0.386570 & 1.000000 & -0.968873 & -0.999772 \\
OE & -0.48950 & -0.99132 & -0.14677 & -0.148863 & -0.96883 & 1.000000 & 0.965897 \\
TR & -0.69388 & -0.98774 & -0.38357 & -0.399159 & -0.99972 & 0.965897 & 1.000000 \\
\hline
\end{tabular}

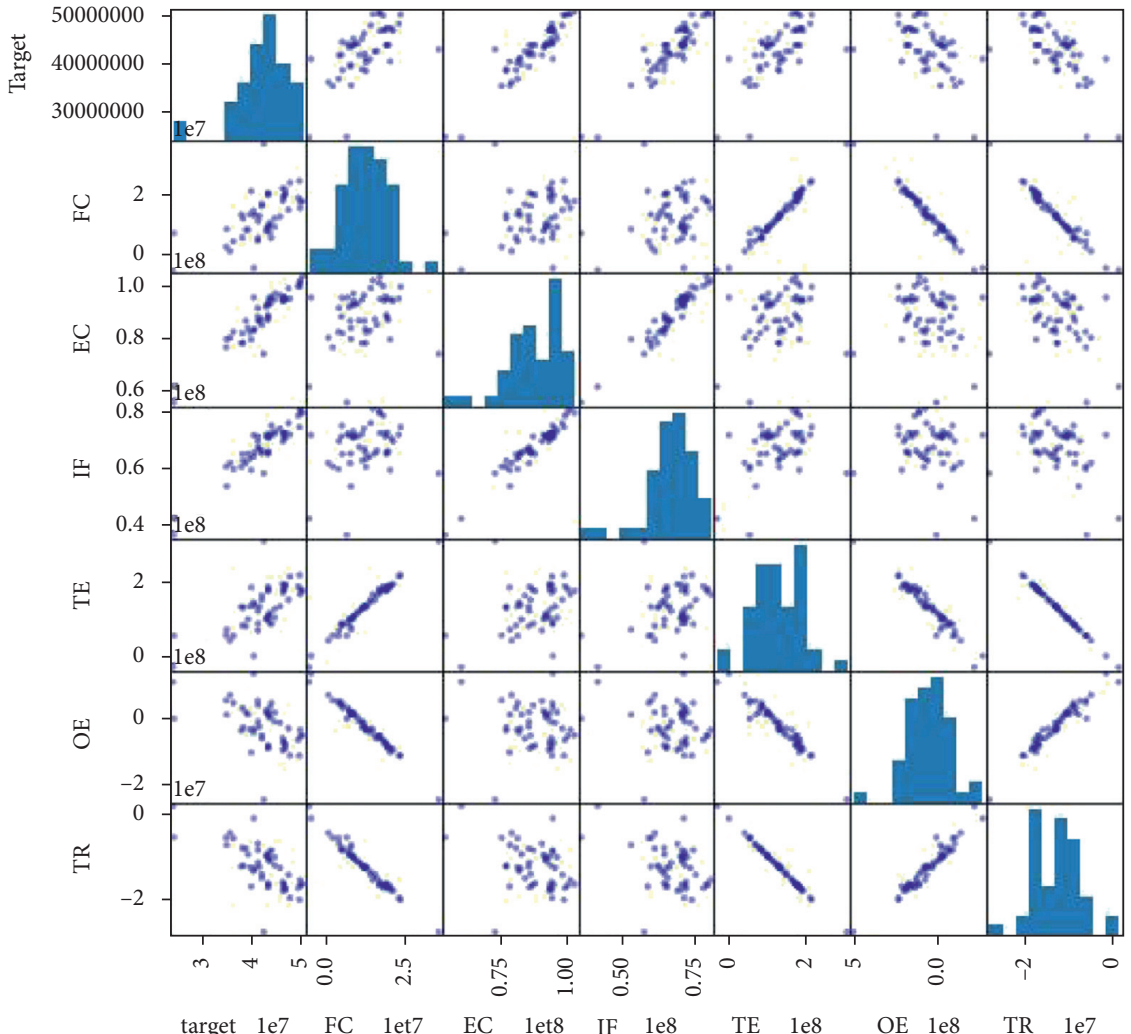

FIGURE 7: Linear trend chart.

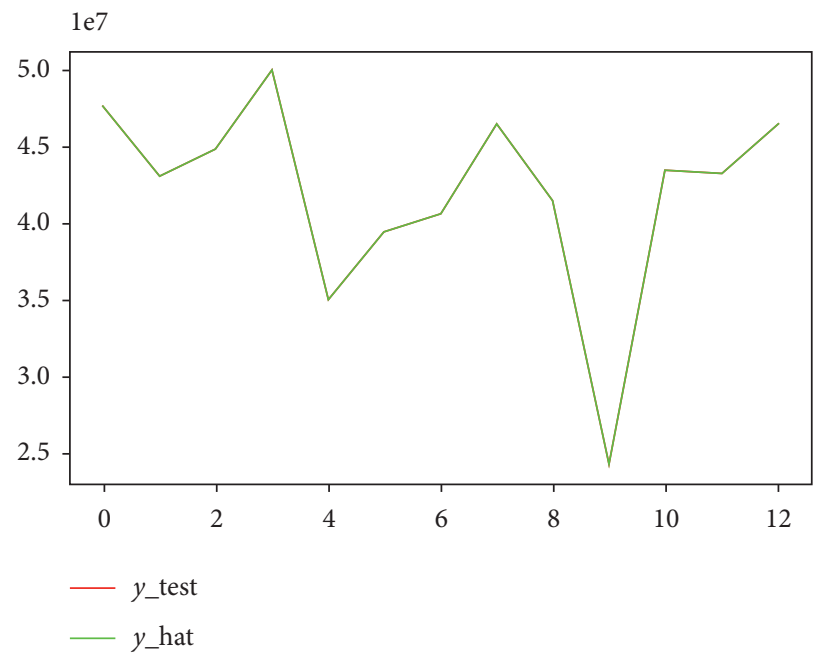

FIGURE 8: Comparison of predicted and real values. 


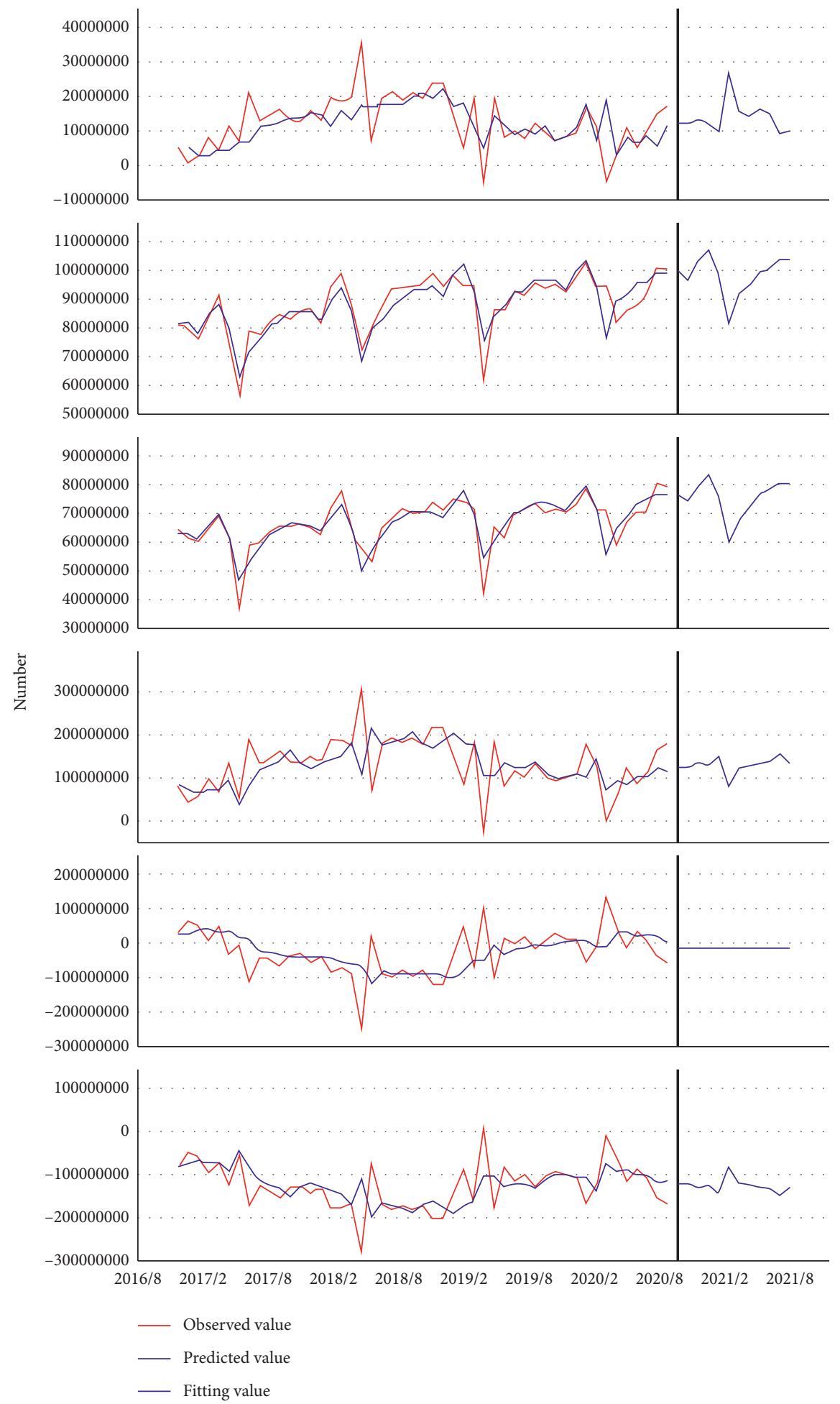

Figure 9: Time series projections for indicators.

First of all, from the level of financial development, the instability of the current international financial situation, coupled with the downward situation of the financial and economic development of the United States during the Trump administration, will have a negative impact on the domestic financial and economic development to a certain extent. In order to counteract the negative impact of the instability of the financial and economic situation in the United States on the domestic economic development, the relevant domestic government departments should introduce policies to control the scale of foreign investment in China and foreign exchange rate control and control the impact of American overseas funds on domestic economic and financial development. At the same time, central banks 


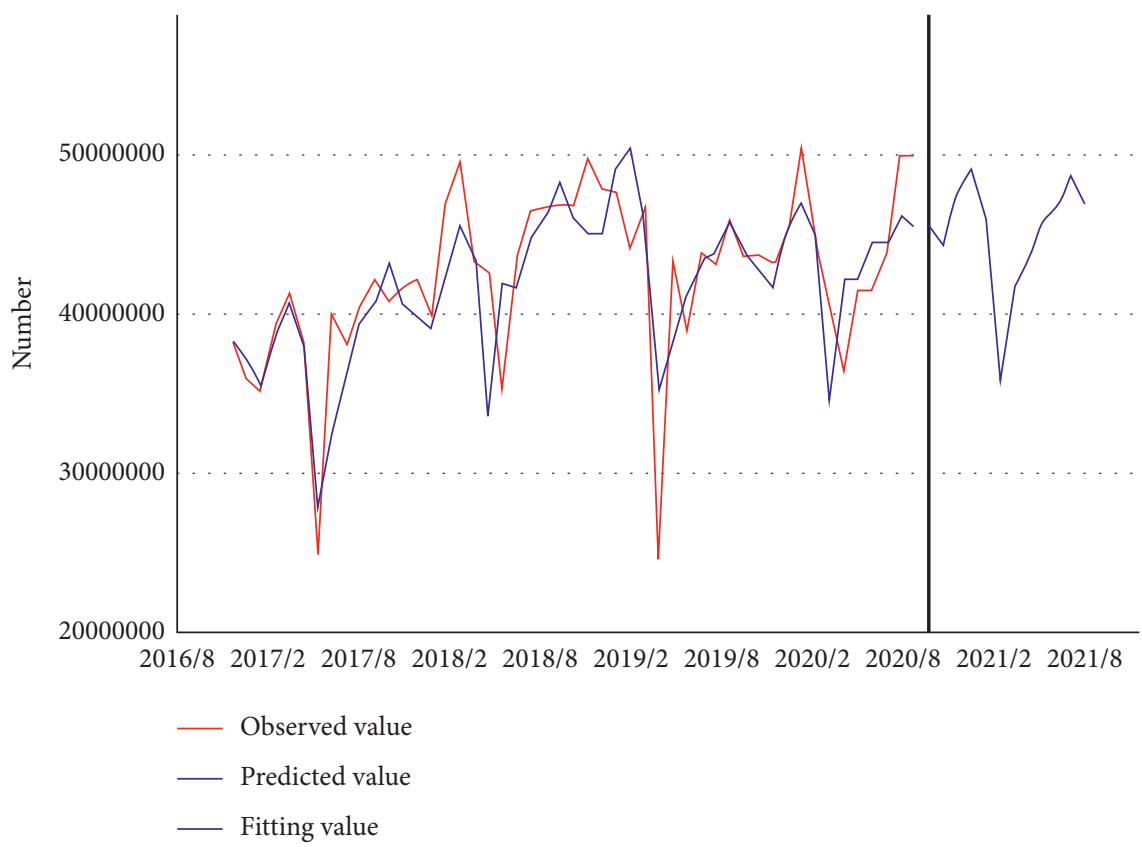

Figure 10: Total value of the time series forecast trend in China.

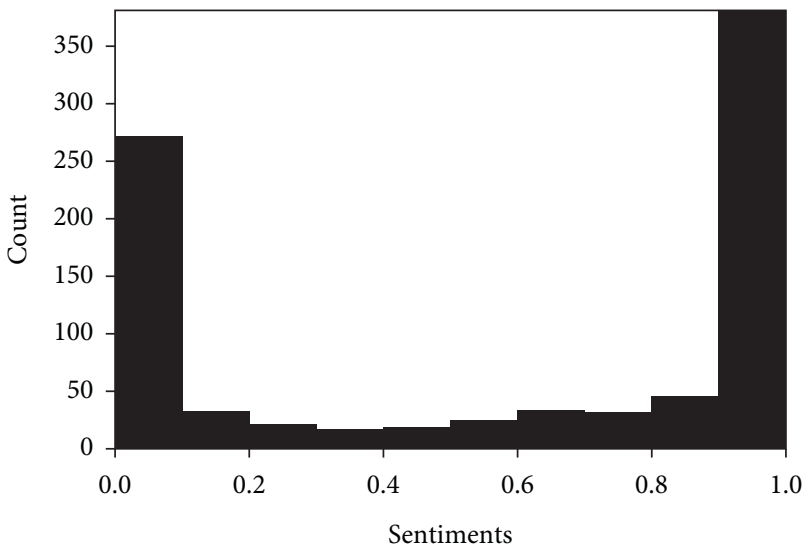

FIgURE 11: Polarity of the popular support in the US election.

and local commercial banks should also monitor the flow of the foreign capital in the United States, prevent the foreign capital from entering the domestic securities and stock market on a large scale, and reduce the impact of the foreign capital on the domestic economic and financial field.

Second, from the environmental protection level, Trump was more inclined to expand the use and development of nonrenewable energy sources such as oil and natural gas during his tenure and withdrew from the Paris Agreement on environmental protection, which undoubtedly made the international climate environment worse in recent years. Biden's policy is to increase investment in new energy and to re-enter the Paris Pact. Relevant government departments in China should continue to adhere to the principles of environmental protection and the development concept of green development [25], do not overuse traditional energy, and promote the use of new energy so that domestic energy use can be more sustainable and improve the domestic

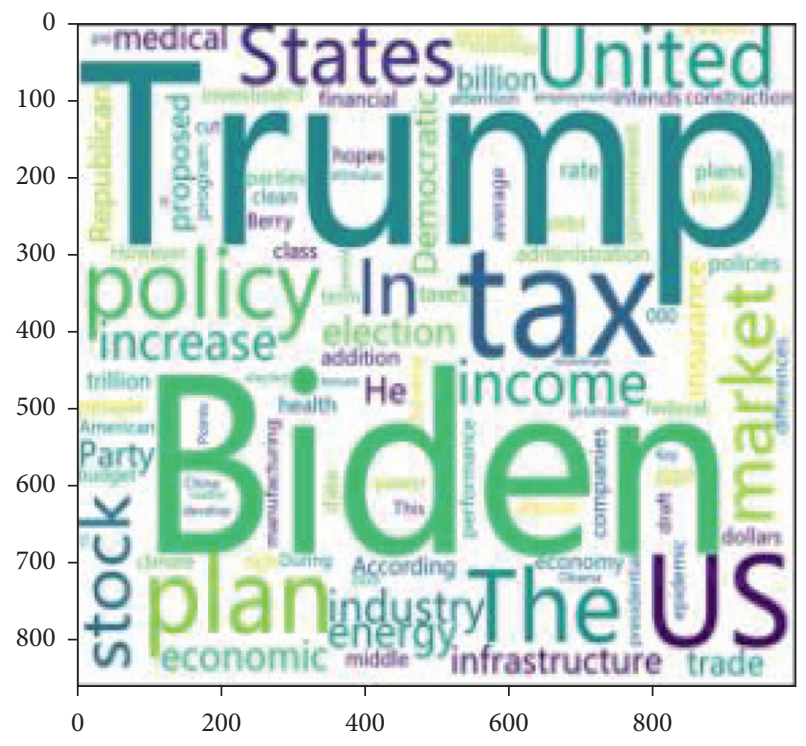

FIgURE 12: The US election word cloud.

environment. Then, the trend of global warming can be alleviated to a certain extent.

Moreover, at the infrastructure level, the current US presidential candidates still attach great importance to infrastructure construction in the United States, especially for infrastructure such as high-speed rail and road in the United States. Both presidential candidates advocate continued investment in US infrastructure. For the domestic infrastructure construction in China, the relevant government departments should pay more attention to the investment of domestic infrastructure construction. At the same time, the China Development Bank should also increase its investment in domestic infrastructure such as roads, railways, and 
high-speed rail and raise funds by issuing government bonds in order to ensure that the domestic infrastructure coverage can reach the world average [26].

From the foreign trade level, during Trump's administration, China's exports and imports of goods to the United States were greatly affected by the Sino-US trade war, especially the domestic $5 \mathrm{G}$ communications, electronic technology products, and high-tech products, and other areas of exports and imports were subject to unilateral sanctions by the United States. For China's foreign trade, China should actively start trade negotiations with the United States. At the same time, it is necessary to increase the development of the product markets of other countries in the world, thus slowing down the restrictive role of the United States in China's foreign trade products and reducing the negative impact of the Sino-US trade war on the export and import of domestic foreign trade enterprises.

In addition, from the employment level, during the Trump administration, the unemployment rate in the United States remained high, and the social problems caused by the high unemployment rate were endless, which to a large extent attracted the attention of the United States government and took measures to remedy it. For China's domestic employment situation, the domestic employment situation is relatively moderate. Relevant government departments in China should introduce development policies to promote domestic employment and try to solve the problem of domestic population employment. In order to prevent the domestic employment environment from being affected, the government should promote enterprises and units to increase the recruitment of foreign personnel to stabilize the domestic employment environment [27].

Finally, at the tax level, during Trump's administration, there was a tax reform bill that advocated large-scale tax cuts, while Biden advocated increasing taxes on the rich in the United States and increasing tax investment in public services. For China's domestic tax policy recommendations, China's relevant government departments should introduce corresponding tax reform policies to strengthen tax control. At the same time, it is also necessary to reduce the tax pressure on low- and middle-income groups, and the tax intensity of domestic high-income groups can be appropriately improved to balance the domestic tax environment so that the government's tax revenue can be truly applied to social public service investment, and the tax public service function can be well played.

\section{Conclusion}

In this paper, stepwise regression, principal component analysis, factor analysis, machine learning logic regression, and time series prediction are used to analyze the economic impact of the US presidential election on the United States and China. The use of a variety of models can better reflect the policy indicators of the President of the United States in various strategic development areas and development focus and attention, so as to infer the possible impact of different candidates on the economy of the United States and China. Finally, emotional analysis and text mining are used to collect and sort out the text data of
American folk comments on the government policy. Avoid errors and deviations caused by manual data processing, reduce the misleading policy analysis caused by manual analysis, and improve the effectiveness of countermeasures and suggestions for China's economic development.

The analysis of this paper also has shortcomings. The existence of extreme values will reduce the analysis effect and accuracy of the regression model, and there will be large analysis errors when the dimension and order of magnitude of the data types are not equal. Then, the analysis results of the principal component analysis model deviate from the actual value. In addition, the emotional analysis model may produce emotional deviation in the collection of text data, which makes the collected text data have a certain emotional tendency, which makes the results analyzed by the model inconsistent with the actual situation. These all need further improvement.

For the improvement of the model, the integration and optimization of the model are mainly carried out by the way of the composite model so that the analysis error of the single model can be effectively reduced, and the overall analysis effect and accuracy of the model can be improved. Using the composite model of the principal component analysis model and factor analysis model to solve the problem, the data types of each index can be reduced reasonably so that the data types of each index can meet the standard of model analysis. The accuracy of parameter estimation of the composite model can be improved. By establishing the compound model of the text mining model and emotion analysis model to improve the model, we can get the emotional tendency level and word cloud distribution of American folk to the American presidential election more accurately and then provide more guiding policy advice for the development of China's economic-related fields.

\section{Data Availability}

The data used to support the findings of this study are included within the article.

\section{Conflicts of Interest}

The authors declare that they have no conflicts of interest.

\section{Acknowledgments}

This study was funded by the Humanities and Social Sciences Research Major Project of the Education Department of Anhui Province (SK2017A0452), Teaching and Research Fund Project of the Education Department of Anhui Province (2020jyxm0017 and 2018jyxm1305), "First-Class Course" of Anhui University of Finance and Economics (acylkc202008), and Teaching and Research Fund Project of the Anhui University of Finance and Economics (acjyyb2020011 and acjyyb2020014).

\section{References}

[1] J. Chen, "Trump administration's Asia-Pacific trade policy analysis," Shanghai Institute of International Studies, vol. 11, no. 8, pp. 1-77, 2017. 
[2] M. M. Wu, "Trump administration under the Sino-US trade friction analysis," Shanghai Academy of Social Sciences, vol. 17, no. 12, pp. 1-74, 2018.

[3] J. W. Yin, "The domestic political logic of consensus change-_the stability analysis of Sino-US strategic consensus after Trump came to power," Contemporary World and Socialism, vol. 40, no. 1, pp. 34-41, 2019.

[4] D. Wang and B. Y. Sun, "Trump's vision of China policy," Modern International Relations, vol. 36, no. 12, pp. 15-23, 2016.

[5] W. Fan, "Application of stepwise regression analysis method in reservoir parameter prediction," Journal of Xi'an University of Science and Technology, vol. 34, no. 3, pp. 350-355, 2014.

[6] Y. L. Hu and J. M. Zhu, "Comparative analysis of stock price prediction based on stepwise regression and BP neural network," Journal of Liaoning University of Technology (Natural Science Edition), vol. 39, no. 3, pp. 201-205, 2019.

[7] L. J. Cao and X. P. Zhang, "Evaluation of water resources capacity in gansu Province based on principal component analysis," Geography of Arid Zones, vol. 40, no. 4, pp. 906-912, 2017.

[8] Z. B. Xiong, "Research on credit evaluation model based on nonlinear principal component analysis, quantitative economic," Technological and Economic Studies, vol. 30, no. 10, pp. 138-150, 2013.

[9] H. Y. Cai, Z. D. Feng, and Z. H. Huang, "Method for central extraction of structural light stripe based on principal component analysis," Laser in China, vol. 42, no. 3, pp. 278-283, 2015.

[10] X. Wang, Y. H. Wang, L. Su et al., "Construction and evaluation of the index system of integration degree of national high-tech zone-Cbased on factor analysis and entropy method," Science and Technology Management, vol. 35, no. 7, pp. 79-88, 2014.

[11] X. Cheng, Y. G. Guan, W. P. Zhang, and C. Tang, "Mechanical fault diagnosis method for high voltage circuit breaker based on factor Analysis and support vector machine algorithm," Journal of Electrical Technology, vol. 29, no. 7, pp. 209-215, 2014.

[12] N. Yao, Z. Y. Gao, Q. Wang, and F. B. Zhu, "Construction and implementation of a support model for diagnosis of coronary heart disease based on machine learning," Wireless Internet Technology, vol. 17, no. 9, pp. 135-138, 2020.

[13] A. H. Hou, W. Gao, and L. Wang, "A study on the method of detection of traffic exception based on logical regression model," Journal of Engineering Mathematics, vol. 34, no. 5, pp. 479-489, 2017.

[14] M. N. Yang, J. Shen, and J. J. Zhang, "Research on patent quality assessment based on machine learning," Computer and Digital Engineering, vol. 47, no. 7, pp. 1743-1747, 2019.

[15] J. Z. Feng, F. J. Liu, and H. Jiang, "Prediction of clinical death in patients with craniocerebral injury: a principal component analysis-logic regression model based on machine learning," Journal of Clinical Neurosurgery, vol. 16, no. 2, pp. 99-103, 2019.

[16] Q. Y. Jiang, "A stock trading decision recommendation system based on time series prediction," Computer Applications and Software, vol. 34, no. 4, pp. 75-81, 2017.

[17] H. M. Wang, Z. S. Pan, and W. Bai, "Summary of time series prediction methods," Computer Science, vol. 46, no. 1, pp. 21-28, 2019.

[18] Z. D. Tian, X. W. Gao, and T. Shi, "Combined kernel function least square support vector machine for chaotic time series prediction," Journal of Physics, vol. 63, no. 16, pp. 70-80, 2014.
[19] S. X. Lun, J. Lin, and X. S. Yao, "Time series prediction based on small world echo state network," Automatic Chemical Reporting, vol. 41, no. 9, pp. 1669-1679, 2015.

[20] Y. H. Zhang, X. F. Zhu, C. Y. Xu et al., "A hybrid recommendation method for deep emotion analysis and multi-view collaborative fusion based on user reviews," Journal of Computer Science, vol. 42, no. 6, pp. 1316-1333, 2019.

[21] L. Xiao, G. Chen, and J. Y. Liu, "Research on enterprise product-level competitor identification based on emotional analysis_- using user comments as data source," The Research Library and Information Services, vol. 60, no. 1, pp. 83-90, 2016.

[22] A. B. Hu, J. Zhang, X. P. Lei et al., "A review on the subject analysis of patent technology based on text mining," Intelligence Magazine, vol. 32, no. 12, pp. 88-92, 2013.

[23] Y. Wang, X. Xu, X. G. Feng et al., "Study on tourism image perception of ancient town based on text mining_- taking zhujiajiao as an example," Tourism Science, vol. 27, no. 5, pp. 86-95, 2013.

[24] C. Zhan, "The analysis of the skills needs of professional talents based on text mining-— taking E-commerce specialty as an example," Library Forum, vol. 37, no. 5, pp. 116-123, 2017.

[25] J. M. Zhu, Y. Chen, and S. Zhang, "Analysis of the impact of climate change on national vulnerability based on fuzzy comprehensive evaluation," Discrete Dynamics in Nature and Society, vol. 2020, Article ID 3527540, 10 pages, 2020.

[26] J.-B. Liu, J. Zhao, and J. Min, "The Hosoya index of graphs formed by a fractal graph," Fractals-Complex Geometry Patterns and Scaling, vol. 27, no. 8, 2019.

[27] J.-M. Zhu, L. Wang, and J.-B. Liu, "Eradication of Ebola based on dynamic programming," Computational and Mathematical Methods in Medicine, vol. 2016, p. 9, Article ID 1580917, 2016. 